Strazicich, M.C., Lee, J., \& Day, E. (2004). Are Incomes Converging Among OECD Countries? Time Series Evidence with Two Structural Breaks. Journal of Macroeconomics, 26(1): 131-145 (March 2004). Published by Elsevier (ISSN: 0164-0704). http://0-dx.doi.org.wncln.wncln.org/10.1016/j.jmacro.2002.11.001

\title{
Are incomes converging among OECD countries? Time series evidence with two structural breaks
}

Mark C. Strazicich, Junsoo Lee, and Edward Day

\begin{abstract}
Time series from fifteen OECD countries for the period 1870-1994 are examined to determine if per capita incomes are stochastically converging. To perform our tests, we utilize a minimum Lagrange multiplier unit root test that endogenously determines two structural breaks in level and trend. In contrast to other tests, our test is not subject to rejections of the null in the presence of a unit root with break(s). Overall, our empirical findings provide significant evidence to support that incomes are stochastically converging. One or two permanent breaks in relative income are identified for each country, most often around the two World Wars.
\end{abstract}




\section{INTRODUCTION}

An important prediction of the Solow (1956) growth model is that given the same savings rate, population growth, and technology, economies will "converge absolutely" to the same per capita income in the long-run steady-state. As such, convergence implies that countries with relatively low initial levels of income will grow faster than countries with relatively high initial levels of income in order to catch-up. Given persistent heterogeneous characteristics, the Solow model predicts that incomes will "converge conditionally" to their own steady-state or "compensating differential".

Numerous studies have empirically examined the convergence hypothesis with varying results. Cross-sectional studies, such as Baumol (1986), Barro (1991), Barro and Sala-i-Martin, 1991 and Barro and Sala-i-Martin, 1992, and Mankiw et al. (1992) find general support for convergence among the industrial countries and their regions. ${ }^{2}$ In contrast to the cross-sectional studies, the time series results are less clear. For example, Quah (1990), using panel data, and Bernard and Durlauf (1995), using (univariate) cointegration tests, find little evidence of income convergence among large groups of countries. Contrary to this, Carlino and Mills (1993) and Loewy and Papell (1996) utilize one-break exogenous and endogenous unit root tests, respectively, and find support for convergence among the US regions. Fleissig and Strauss (2001) examine OECD countries with a variety of panel unit root tests and find, in general, support for convergence only in the post-WWII period.

In this paper, we utilize the time series methodology suggested in Carlino and Mills (1993) and test for "stochastic convergence". Stochastic convergence implies that shocks to income of country " " relative to the average income will be temporary. For each country, we examine the null hypothesis that incomes are diverging and test for a unit root in the log of the ratio of per capita income relative to the average. Failure to reject the unit root null hypothesis indicates evidence against income convergence. In this case, following a shock to relative income in country $i$ there is no tendency for per capita income to return to the average; thus implying that incomes diverge. Contrary to this, rejection of a unit root supports the alternative hypothesis that shocks to relative income are temporary, implying that incomes converge. Since the test includes a constant term, stochastic convergence implies that incomes converge to a countryspecific compensating differential. Therefore, stochastic convergence is consistent with conditional convergence.

Our paper differs from previous works in several ways. First, whereas other time series tests that support convergence do so with panel data we find strong support for convergence in single country (univariate) tests. Second, by allowing for two structural breaks the ability to reject a false unit root null hypothesis can be significantly increased. This may explain why previous time series tests that did not allow for structural breaks found less evidence of convergence. Third, as we will explain below, our testing methodology is not subject to rejections of the null in the presence of a unit root with break(s). Whereas previous endogenous break unit root tests might reject the null hypothesis, it is possible that rejection of the null indicates a unit root with break(s) rather than a stationary series with break(s). Thus, researchers utilizing the previous tests might incorrectly conclude that incomes converge when in fact the opposite is the case. 
Fortunately, the empirical test that we employ is not subject to this type of spurious rejection. With our test methodology, a rejection of the null hypothesis unambiguously implies stationarity and stochastic convergence.

To test for convergence we examine real per capita incomes in fifteen industrial (OECD) countries over the time period 1870-1994. To perform our tests, we utilize the minimum Lagrange multiplier (LM) unit root test developed by Lee and Strazicich (2003). The test allows for two structural breaks in level and trend and determines the break points endogenously from the data. Given a time span of 125 years, we expect that major events, such as two World Wars and the Great Depression, might significantly impact the time path of relative incomes. As such, allowing for breaks can potentially strengthen our results by more correctly specifying the model. Overall, our empirical findings provide significant evidence that incomes are stochastically converging among OECD countries.

The remainder of the paper proceeds as follows. Section 2 describes our testing methodology. Section 3 describes the data, performs the tests, and discusses the results. Section 4 discusses the structural breaks. Section 5 summarizes and concludes.

\section{TESTING METHODOLOGY}

Perron (1989) initially showed that failure to allow for an existing structural break leads to a bias that reduces the ability to reject a false unit root null hypothesis. To provide a remedy, Perron proposed allowing for one known, or "exogenous," structural break in the augmented DickeyFuller (ADF, hereafter) unit root test. Following Perron (1989), Zivot and Andrews (1992, ZA hereafter), and Perron (1997), among others, proposed determining the break point "endogenously" from the data. The ZA test selects the break point where the $t$-statistic that tests the unit root null is minimized (i.e., the most negative) and, therefore, least favorable to the unit root hypothesis. A similar test is developed by Perron (1997), which selects the break point where the absolute value of the $t$-statistic on the break term is maximized.

A potential problem common to the ADF-type endogenous break unit root tests is that they derive their critical values while assuming no break(s) under the null. Nunes et al. (1997) show that this assumption leads to size distortions in the presence of a unit root with break. Lee and Strazicich (2001) further investigate this issue and discover the source of the size distortions. In the presence of a unit root with break, the ZA and Perron (1997) tests tend to select the break point where bias and size distortions are the greatest. Lumsdaine and Papell (1997, LP hereafter), extend the ZA test to allow for two breaks in level and trend. Lee and Strazicich (2003) demonstrate that in the presence of a unit root with breaks, the same outcome occurs as in the one-break tests. As a result, when utilizing these ADF-type endogenous break unit root tests researchers might conclude that a time series is trend stationary, when in fact the series is nonstationary with break(s). In this regard, "spurious rejections" may result.

To avoid problems of bias and spurious rejections, we utilize the endogenous two-break LM unit root test derived in Lee and Strazicich (2003). In contrast to the ADF-type tests, size properties 
of the two-break LM test are unaffected by breaks under the null. Thus, results using the LM test are more revealing, since rejection of the null unambiguously implies stochastic convergence.

The two-break minimum LM unit root can be described as follows. According to the LM (score) principle, a unit root test statistic can be obtained from the following regression:

$$
\Delta y_{t}=d^{\prime} \Delta Z_{t}+\phi \widetilde{S}_{t-1}+\Sigma \gamma_{i} \Delta \widetilde{S}_{t-i}+\varepsilon_{t},
$$

where $\widetilde{S}_{t}$ is a de-trended series such that $\widetilde{S}_{t}=y_{t}-\widetilde{\psi}_{x}-Z_{t} \widetilde{\delta}, t=2, \ldots, T$. $\widetilde{\delta}$ is a vector of coefficients in the regression of $\Delta y_{t}$ on $\Delta Z_{t}$ and $\widetilde{\psi}_{x}=y_{1}-Z_{1} \widetilde{\delta}$, where $Z_{t}$ is defined below; $y_{1}$ and $Z_{1}$ are the first observations of $y_{t}$ and $Z_{t}$, respectively, and $\Delta$ is the difference operator. $\varepsilon_{t}$ is the contemporaneous error term and is assumed independent and identically distributed with zero mean and finite variance. $\Delta \widetilde{S}_{t-i}, i=1, \ldots, k$, terms are included as necessary to correct for serial correlation. $Z_{t}$ is a vector of exogenous variables defined by the data generating process. Corresponding to the two-break equivalent of Perron's (1989) Model C, with two changes in level and trend, $Z_{t}$ is described by $\left[1, t, D_{1 t}, D_{2 t}, D T_{1 t}^{*}, D T_{2 t}^{*}\right]^{\prime}$, where $D_{j t}=1$ for $t$ ? $T_{\mathrm{B} J}+1, j=1,2$, and zero otherwise, $D T_{j t}^{*}=t_{\text {for }} T_{\mathrm{B} j}+1, j=1,2$, and zero otherwise, and $T_{\mathrm{B} j}$ stands for the time period of the breaks. Note that the test regression (1) involves $\Delta Z_{t}$ instead of $Z_{t}$ so that $\Delta Z_{t}$ becomes $\left[1, B_{1 t}, B_{2 t}, D_{1 t}, D_{2 t}\right]^{\prime}$, where $B_{j t}=\Delta D_{j t}$ and $D_{j t}=\Delta D T_{j t}^{*}, j=1,2$. The unit root null hypothesis is described in Eq. (1) by $\varphi=0$ and the test statistics are defined as follows:

$$
\widetilde{\rho}=T \cdot \widetilde{\phi}
$$

$\widetilde{\tau}=t-$ statistic for the null hypothesis $\phi=0$.

To endogenously determine the location of two breaks $\left(\lambda_{j}=T_{\mathrm{B}} / T, j=1,2\right)$, the minimum $L M$ unit root test uses a grid search as follows:

$$
\operatorname{LM}_{\rho}=\operatorname{Inf}_{\lambda} \widetilde{\rho}(\lambda)
$$

$$
\operatorname{LM}_{\tau}=\operatorname{Inf}_{\lambda} \tilde{\tau}(\lambda) \text {. }
$$

Since results are similar, we discuss only the $L M_{T}$ test. As shown in Lee and Strazicich (2003), critical values for Model $\mathrm{C}$ depend (somewhat) on the location of breaks $\left(\lambda_{j}\right)$. Therefore, we utilize critical values that correspond to the location of the breaks. ${ }^{3}$ 


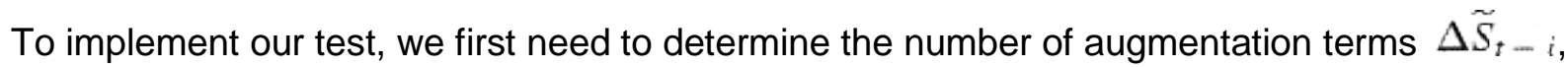
$i=1, \ldots, k$, that correct for serial correlation in Eq. (1). At each combination of break points $\lambda=\left(\lambda_{1}, \lambda_{2}\right)^{\prime}$ in the time interval [0.1T,0.9T] (to eliminate end points), where $T$ is the sample size, we determine $k$ by following a "general to specific" procedure. We begin with a maximum number of lagged first-differenced terms $\max k=8$ and examine the last term to see if it is significantly different from zero at the $10 \%$ level (critical value in an asymptotic normal distribution is 1.645). If insignificant, the maximum lagged term is dropped and the model re-estimated with $k=7$ terms and so on, until either the maximum term is found or $k=0$, at which point the procedure stops. This technique has been shown to perform well as compared to other data-dependent procedures that select the number of lagged augmented terms. ${ }^{4}$

Advantages of the two-break minimum LM unit root test can be summarized as follows. First, the break points are endogenously determined from the data. Second, the test is not subject to spurious rejections in the presence of a unit root with break(s). Third, when the alternative hypothesis is true and spurious rejections are absent, Lee and Strazicich (2003) demonstrate that the two-break minimum LM test has greater or comparable power to the LP test. ${ }^{5}$

\section{DATA AND TEST RESULTS}

We utilize Maddison's (1995) data on annual per capita GDP over the time period 1870-1994 to test for stochastic convergence in fifteen OECD countries. The countries examined are Australia, Austria, Belgium, Canada, Denmark, Finland, France, Germany, Italy, the Netherlands, New Zealand, Norway, Sweden, the United Kingdom (UK), and the United States (US). The data adjusts for purchasing power parity in currencies and international average prices in commodities.

For each country $i$, we examine the natural logarithm of the ratio of per capita real GDP (PCGDP) relative to the average of all countries as follows:

$$
y_{i t}=\ln \left(\mathrm{PCGDP}_{\text {it }} / \text { average } \mathrm{PCGDP}_{t}\right) .
$$

We utilize the endogenous two-break $L M$ unit root test $\left(\mathrm{LM}_{T}\right.$ in (3b)) to examine the log relative income series in (4). Throughout, we consider Model C, which allows for two changes in level and trend. ${ }^{6}$

Results of employing the two-break LM unit root test for the sample period 1870-1994 are shown in Table 1. Ten of the fifteen log relative income series reject the unit root null at the $10 \%$ significance level. Examination reveals that two structural breaks in level $\left(B_{j t}\right)$ and/or trend $\left(D_{j t}\right)$ are significant ( $t$-values significant at $10 \%$ ) in twelve countries, while only one structural break is significant in the three remaining countries (Finland, Italy, and Norway). ${ }^{7}$ 
Table 1

Two-break minimum LM unit root test, sample period 1870-1994

\begin{tabular}{|c|c|c|c|c|}
\hline Country & $\hat{k}$ & $\widehat{T_{\mathrm{B}}}$ & Test statistic & $\begin{array}{l}\text { Critical value } \\
\text { break points }\end{array}$ \\
\hline Australia & 8 & 1890,1945 & -4.958 & $\lambda=(0.2,0.6)$ \\
\hline Austria & 2 & 1943,1950 & $-6.291^{* *}$ & $\lambda=(0.6,0.65)$ \\
\hline Belgium & 1 & 1939,1946 & $-5.883^{* *}$ & $\lambda=(0.56,0.62)$ \\
\hline Canada & 3 & 1916,1940 & $-5.739 * *$ & $\lambda=(0.4,0.6)$ \\
\hline Denmark & 7 & 1888,1938 & $-6.761^{* * *}$ & $\lambda=(0.2,0.6)$ \\
\hline Finland & 3 & $1926,1978 \mathrm{n}$ & $-6.134^{* *}$ & $\lambda=(0.4,0.8)$ \\
\hline France & 3 & 1939,1949 & $-8.144^{* * *}$ & $\lambda=(0.4,0.6)$ \\
\hline Gemmany & 3 & 1943,1953 & $-5.865^{* *}$ & $\lambda=(0.4,0.6)$ \\
\hline Italy & 1 & $1912,1946 \mathrm{n}$ & -5.120 & $\lambda=(0.4,0.6)$ \\
\hline Netherlands & 1 & 1938,1947 & $-6.054^{* *}$ & $\lambda=(0.4,0.6)$ \\
\hline New Zealand & 0 & 1925,1949 & -5.162 & $\lambda=(0.4,0.6)$ \\
\hline Norway & 7 & $1918,1967 \mathrm{n}$ & $-5.770^{* *}$ & $\lambda=(0.4,0.8)$ \\
\hline Sweden & 8 & 1909,1943 & -4.718 & $\lambda=(0.4,0.6)$ \\
\hline UK & 5 & 1938,1953 & -4.576 & $\lambda=(0.55,0.67)$ \\
\hline US & 8 & 1937,1955 & $-6.164^{* *}$ & $\lambda=(0.54,0.69)$ \\
\hline
\end{tabular}

Notes: $\hat{k}$ is the optimal number of lagged first-differenced terms included in the unit root test to correct for serial correlation. $\widehat{T}_{\mathrm{B}}$ denotes the estimated break points. $\mathrm{n}$ denotes that the identified break point was not significant at the $10 \%$ level. Critical values are shown below for the two-break minimum LM unit root test with linear trend (Model C) at the $1 \%, 5 \%$, and $10 \%$ levels for a sample of size $T=100$, respectively. The critical values depend (somewhat) on the location of the breaks $\lambda=\left(T_{\mathrm{B} 1} / T, T_{\mathrm{B} 2} / T\right)$ and are symmetric around $\lambda$ and $(1-\lambda)$. Critical values at additional break points can be interpolated. $*, * *$, and $* * *$ denote significant at the $10 \%, 5 \%$, and $1 \%$ levels, respectively. The critical values shown below come from Table 2 in Lee and Strazicich (2003).

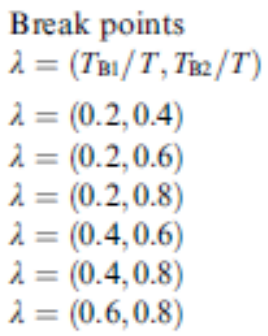

\begin{tabular}{lll} 
Critical values & \\
$1 \%$ & $5 \%$ & $10 \%$ \\
\hline-6.16 & -5.59 & -5.27 \\
-6.41 & -5.74 & -5.32 \\
-6.33 & -5.71 & -5.33 \\
-6.45 & -5.67 & -5.31 \\
-6.42 & -5.65 & -5.32 \\
-6.32 & -5.73 & -5.32
\end{tabular}

For Finland, Italy, and Norway a one-break unit root test appears more appropriate. Therefore, we want to determine if including two breaks instead of one can adversely affect power to reject the null for these three countries. To check for this possibility, we perform additional tests for these three countries using the one-break minimum LM unit root test developed in Lee and Strazicich (1999). The results are shown in Table 2. The one-break test results are essentially unchanged from the two-break results, except that Norway now rejects the unit root null at the stronger $1 \%$ significance level as compared to the previous $5 \%$ level. One-break point is significant in each country at the $10 \%$ level. The one country out of these three that failed to reject the unit root null in the two-break test (Italy) remains unable to reject the null in the onebreak test suggesting that loss of power is not a factor in this case. ${ }^{8}$ 
Table 2

One-break minimum LM unit root test, 1870-1994

\begin{tabular}{lllll}
\hline Series & $\hat{k}$ & $\widehat{T}_{\mathrm{B}}$ & Test statistic & $\begin{array}{l}\text { Critical value } \\
\text { break points }\end{array}$ \\
\hline Finland & 7 & 1929 & $-4.864^{* *}$ & $\lambda=0.4$ \\
Italy & 1 & 1959 & -3.776 & $\lambda=0.8(=0.2)$ \\
Norway & 7 & 1918 & $-5.269^{* * *}$ & $\lambda=0.4$ \\
\hline
\end{tabular}

Notes: $\hat{k}$ is the optimal number of lagged first-differenced terms included in the unit root test to correct for serial correlation. $\widehat{T}_{\mathrm{B}}$ denotes the estimated break point. $\mathrm{n}$ denotes that the identified break point was not significant at the $10 \%$ level. Critical values are shown below for the one-break minimum LM unit root test with linear trend (Model C) at the $1 \%, 5 \%$, and $10 \%$ levels for a sample of size $T=100$, respectively. Critical values are symmetric around $\lambda$ and $(1-\lambda)$. Critical values at additional break points can be interpolated. $*, * *$, and $* * *$ denote significant at the $10 \%, 5 \%$, and $1 \%$ levels, respectively. The critical values shown below come from Lee and Strazicich (1999).

\begin{tabular}{llll} 
Break point & \multicolumn{2}{l}{ Critical values } & \\
$\lambda=\left(T_{\mathrm{B}} / T\right)$ & $1 \%$ & $5 \%$ & $10 \%$ \\
\cline { 2 - 4 }$\lambda=0.1$ & -5.11 & -4.50 & -4.21 \\
$\lambda=0.2$ & -5.07 & -4.47 & -4.20 \\
$\lambda=0.3$ & -5.15 & -4.45 & -4.18 \\
$\lambda=0.4$ & -5.05 & -4.50 & -4.18 \\
$\lambda=0.5$ & -5.11 & -4.51 & -4.17
\end{tabular}

To check the robustness of our results, we will repeat the two-break tests utilized above for three smaller sub-samples: 1880-1994 (i.e., omitting the first 10 years); the post-WWI years of 1919-1994; and the post-WWII years of 1946-1994..$^{9}$ Results are displayed in Table 3. For convenience, we include the summary statistics of the full sample period in the last three columns. Results for the 1880-1994 period are essentially unchanged from the full sample, with the exception that Germany no longer rejects divergence. For the post-WWI years, the null hypothesis implying divergence is rejected in twelve out of fifteen countries (at the $10 \%$ level of significance). These results provide stronger evidence for stochastic convergence, and suggest that the tendency for economies to converge was more pronounced after WWI. Finally, the postWWII years provide weaker evidence of convergence as the null is rejected in only 5 of 15 countries. However, the significance of the post-WWII results should be taken with reservation. Given a sample size of $T=49$, the power of the unit root test is diminished. 
Table 3

Two-break minimum LM unit root test, sub-sample comparisons

\begin{tabular}{|c|c|c|c|c|c|c|c|c|c|c|c|c|}
\hline \multirow[t]{2}{*}{ Country } & \multicolumn{3}{|c|}{$1880-1994$} & \multicolumn{3}{|c|}{ 1919-1994 } & \multicolumn{3}{|c|}{ 1946-1994 } & \multicolumn{3}{|c|}{$1870-1994$} \\
\hline & $\hat{\hat{k}}$ & $\widehat{T}_{\mathrm{B}}$ & $\begin{array}{l}\text { Test } \\
\text { statistic }\end{array}$ & $\hat{\hat{k}}$ & $\widehat{T}_{\mathrm{B}}$ & $\begin{array}{l}\text { Test } \\
\text { statistic }\end{array}$ & $\hat{k}$ & $\widehat{T}_{\mathrm{B}}$ & $\begin{array}{l}\text { Test } \\
\text { statistic }\end{array}$ & $\hat{k}$ & $\widehat{T}_{\mathrm{B}}$ & $\begin{array}{l}\text { Test } \\
\text { statistic }\end{array}$ \\
\hline Australia & 8 & 1914,1958 & -4.77 & 8 & $1941,1959 \mathrm{n}$ & $-6.82^{* * * *}$ & 1 & 1966,1980 & -5.11 & 8 & 1890,1945 & -4.96 \\
\hline Austria & 2 & 1943,1950 & $-6.05^{* *}$ & 8 & 1943,1956 & $-7.06^{* * *}$ & 7 & 1971, 1975 & -3.41 & 2 & 1943,1950 & $-6.29 * *$ \\
\hline Belgium & 6 & 1917,1940 & $-5.75^{* *}$ & 6 & 1938,1952 & $-5.88^{* * *}$ & 4 & 1960,1982 & -4.94 & 1 & 1939,1946 & $-5.88^{* *}$ \\
\hline Canada & 5 & 1916,1940 & $-5.90^{* *}$ & 5 & 1938,1953 & $-5.89^{* *}$ & 0 & 1966,1988 & $-5.33^{*}$ & 3 & 1916,1940 & $-5.74^{* *}$ \\
\hline Denmark & 5 & 1938,1949 & $-7.45^{* * *}$ & 7 & 1938,1950 & $-7.34^{* * *}$ & 4 & 1963,1976 & -5.27 & 7 & 1888,1938 & $-6.76^{* * *}$ \\
\hline Finland & 3 & 1913,1925 & $-6.34^{* * *}$ & 3 & $1939,1986 \mathrm{n}$ & $-6.13^{* *}$ & 3 & 1962,1985 & $-6.38^{* *}$ & 3 & $1926,1978 \mathrm{n}$ & $-6.13^{* *}$ \\
\hline France & 3 & 1939,1949 & $-7.88^{* * *}$ & 5 & 1938,1948 & $-8.70^{* * *}$ & 2 & $1956,1970 \mathrm{n}$ & -4.51 & 3 & 1939,1949 & $-8.14^{* * *}$ \\
\hline Germany & 3 & 1943,1953 & -5.16 & 8 & 1944,1957 & $-9.78^{* * *}$ & 2 & 1956,1965 & $-5.54^{*}$ & 3 & 1943,1953 & $-5.87^{* *}$ \\
\hline Italy & 1 & $1912,1946 n$ & -4.95 & 1 & 1941,1952 & -5.14 & 6 & 1956,1970 & -4.95 & 1 & $1912,1946 n$ & -5.12 \\
\hline Netherlands & 1 & 1938,1947 & $-5.72^{* *}$ & 1 & 1940,1947 & $-7.92^{* * *}$ & 7 & 1960,1979 & -5.06 & 1 & 1938,1947 & $-6.05^{* *}$ \\
\hline New Zealand & 5 & 1920,1945 & -4.82 & 5 & 1934,1946 & $-6.54^{* * *}$ & 5 & $1965,1974 \mathrm{n}$ & $-6.47^{* * *}$ & 0 & 1925,1949 & -5.16 \\
\hline Norway & 7 & $1918,1967 \mathrm{n}$ & $-5.45^{*}$ & 7 & 1951,1974 & $-5.78^{* *}$ & 1 & 1970 n, 1986 & -5.22 & 7 & $1918,1967 \mathrm{n}$ & $-5.77^{* *}$ \\
\hline Sweden & 8 & 1913,1943 & -4.71 & 1 & 1947,1961 & -5.25 & 7 & 1959,1974 & -4.50 & 8 & 1909,1943 & -4.72 \\
\hline UK & 3 & 1927,1948 & -4.52 & 8 & 1938,1960 & -4.62 & 7 & $1958,1976 \mathrm{n}$ & -4.89 & 5 & 1938,1953 & -4.58 \\
\hline US & 8 & 1949,1955 & $-5.42^{*}$ & 8 & 1940,1955 & $-6.92^{* * *}$ & 5 & 1964,1972 & $-6.55^{* * *}$ & 8 & 1937,1955 & $-6.16^{* *}$ \\
\hline
\end{tabular}

Notes: $\hat{k}$ is the optimal number of lagged first-differenced terms included in the unit root test to correct for serial correlation. $\widehat{T}_{\mathrm{B}}$ denotes the estimated break points. $\mathrm{n}$ denotes that the identified break point was not significant at the $10 \%$ level. Critical values are shown below for the two-break minimum LM unit root test with linear trend (Model C) at the $1 \%, 5 \%$, and $10 \%$ levels for a sample of size $T=100$, respectively. The critical values depend (somewhat) on the location of the breaks $\lambda=\left(T_{\mathrm{BI}} / T, T_{\mathrm{B} 2} / T\right)$, and are symmetric around $\lambda$ and $(1-\lambda)$. Critical values at additional break points can be interpolated. $*, * *$, and $* * *$ denote significant at the $10 \%, 5 \%$, and $1 \%$ levels, respectively. The critical values shown below come from Table 2 in Lee and Strazicich (2003).

Since only one structural break was found (at the $10 \%$ level of significance) for some countries, we will repeat the tests for these countries using the minimum one-break LM test. The results are shown in Table 4. For 1880-1994, the one-break results for Italy and Norway are essentially unchanged as compared to the two-break test. For the post-WWI period of 1919-1994, using the one-break test, Australia and Finland no longer reject divergence. However, the structural break is not significant for either country (at the $10 \%$ level). Therefore, we performed additional tests for these two countries using the no break LM unit root test of Schmidt and Phillips (1992). The results reject the unit root hypothesis for both countries (at the $5 \%$ level of significance). ${ }^{10}$ Thus, by combining results from the two, one, and no break tests stochastic convergence is supported for twelve of the fifteen countries. For the post-WWII years of 1946-1994 the onebreak results are essentially unchanged as compared to the two-break test. 
Table 4

One-break minimum LM unit root test, sub-sample comparisons

\begin{tabular}{|c|c|c|c|c|c|c|c|c|c|c|c|c|}
\hline \multirow[t]{2}{*}{ Country } & \multicolumn{3}{|c|}{$1880-1994$} & \multicolumn{3}{|c|}{ 1919-1994 } & \multicolumn{3}{|c|}{ 1946-1994 } & \multicolumn{3}{|c|}{ 1870-1994 } \\
\hline & $\bar{k}$ & $\widetilde{T}_{\mathrm{B}}$ & Test statistic & $\bar{k}$ & $\widetilde{T}_{\mathrm{B}}$ & Test statistic & $\hat{k}$ & $\widetilde{T}_{\mathrm{B}}$ & Test statistic & $\bar{k}$ & $\widetilde{T}_{\mathrm{B}}$ & Test statistic \\
\hline Australia & - & - & - & 8 & $1946 n$ & -3.89 & - & - & - & - & - & - \\
\hline Austria & - & - & - & - & - & - & - & - & - & - & - & - \\
\hline Belgium & - & - & - & - & - & - & - & - & - & - & - & - \\
\hline Canada & - & - & - & - & - & - & - & - & - & - & - & - \\
\hline Denmark & - & - & - & - & - & - & - & - & - & - & - & - \\
\hline Finland & - & - & - & 4 & $1929 n$ & -3.75 & - & - & - & 7 & 1929 & $-4.86^{* *}$ \\
\hline France & - & - & - & - & - & - & 2 & 1966 & -2.89 & - & - & - \\
\hline Germany & - & - & - & - & - & - & - & - & - & - & - & - \\
\hline Italy & 1 & 1956 & -3.62 & - & - & - & - & - & - & 1 & 1959 & -3.78 \\
\hline Netherlands & - & - & - & - & - & - & - & - & - & - & & - \\
\hline New Zealand & - & - & - & - & - & - & 5 & 1975 & $-6.06^{* * *}$ & - & & - \\
\hline Norway & 7 & 1918 & $-4.98^{* *}$ & - & - & - & 8 & 1972 & -3.97 & 7 & 1918 & $-5.27^{* * *}$ \\
\hline Sweden & - & - & - & - & - & - & - & - & - & - & - & - \\
\hline UK & - & - & - & - & - & - & 5 & 1972 & -3.30 & - & - & - \\
\hline US & - & - & - & - & - & - & - & - & - & - & - & - \\
\hline
\end{tabular}

Notes: $\hat{k}$ is the optimal number of lagged first-differenced terms included in the unit root test to correct for serial correlation. $\widehat{T}_{\mathrm{B}}$ denotes the estimated break point. $\mathrm{n}$ denotes that the identified break point was not significant at the $10 \%$ level. Critical values are shown below for the one-break minimum LM unit root test with linear trend (Model C) at the $1 \%, 5 \%$, and $10 \%$ levels for a sample of size $T=100$, respectively. Critical values are symmetric around $\lambda$ and ( $1-\lambda$ ). Critical values at additional break points can be interpolated. $*, * *$, and $* * *$ denote significant at the $10 \%, 5 \%$, and $1 \%$ levels, respectively. Critical values are the same as those shown below Table 2 and come from Lee and Strazicich (1999).

Overall, our empirical findings provide significant support for income convergence among OECD countries. As compared to previous univariate time series tests that did not allow for structural breaks, we find stronger support for convergence. For example, Bernard and Durlauf (1995) did not include structural breaks and found little evidence of convergence in their (univariate) cointegration tests. In their univariate ADF tests, Fleissig and Strauss (2001) also found little evidence of convergence. After employing panel unit root tests to increase power, Fleissig and Strauss (2001) again found little evidence of convergence over the time period of 1900-1987. The authors note that structural breaks likely occurred prior to 1948, which reduces the ability of their tests to reject a false unit root hypothesis. The difference in outcomes between the above authors and the present paper are likely due to our allowing for structural breaks. Our empirical findings thus provide noteworthy evidence that structural breaks should be considered in tests for convergence. ${ }^{11}$

To visualize our empirical findings, we superimpose the level and trend breaks identified by the two-break test in Table 1 and plot the log of relative per capita income for each country. Linear trends are then estimated using ordinary least squares to connect the break points. The results are displayed in Fig. 1. Upon examination, it is apparent that most of the log relative income series appear stationary after allowing for structural breaks. 

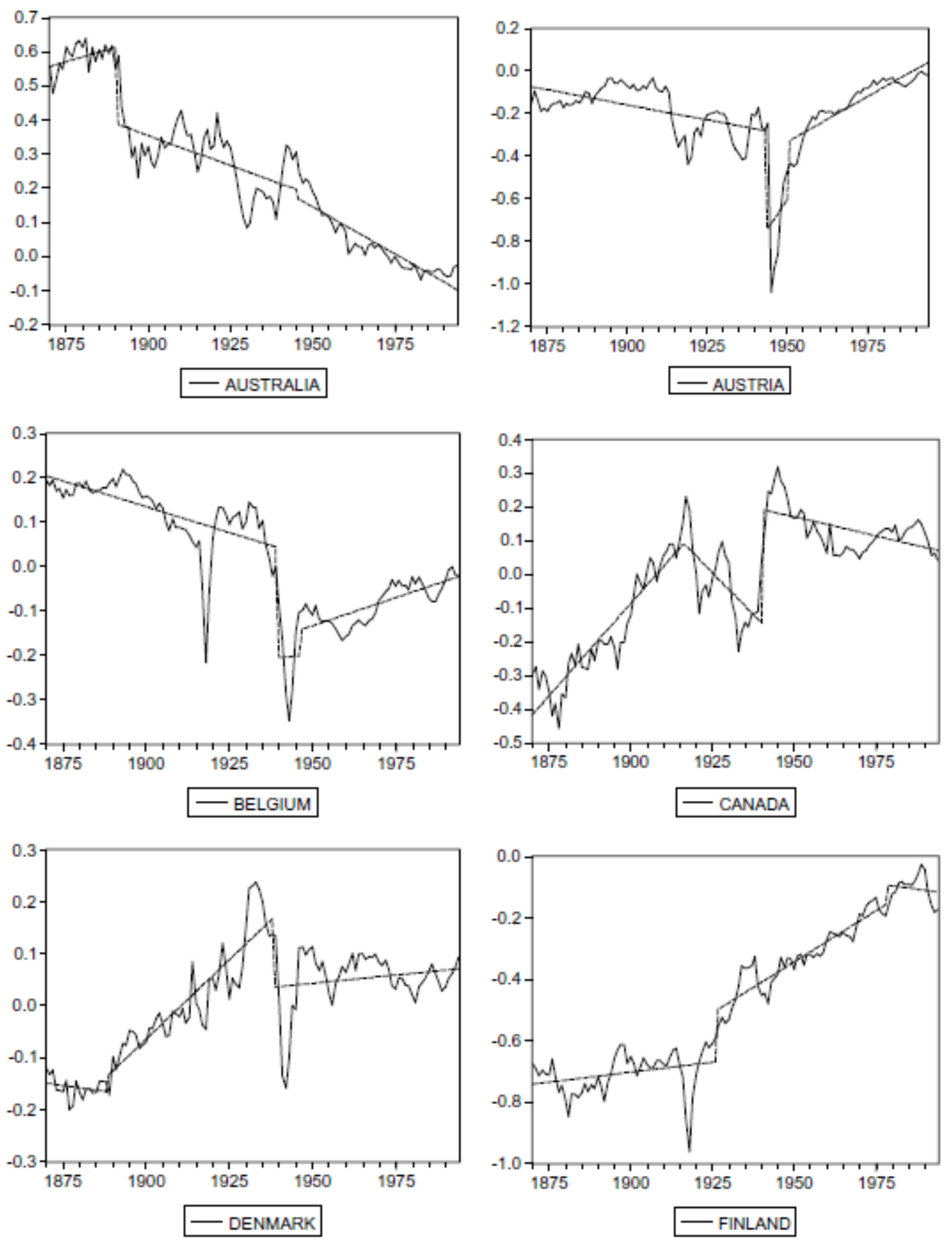

Fig. 1. Log of per capita income relative to the mean, 1870-1994. 

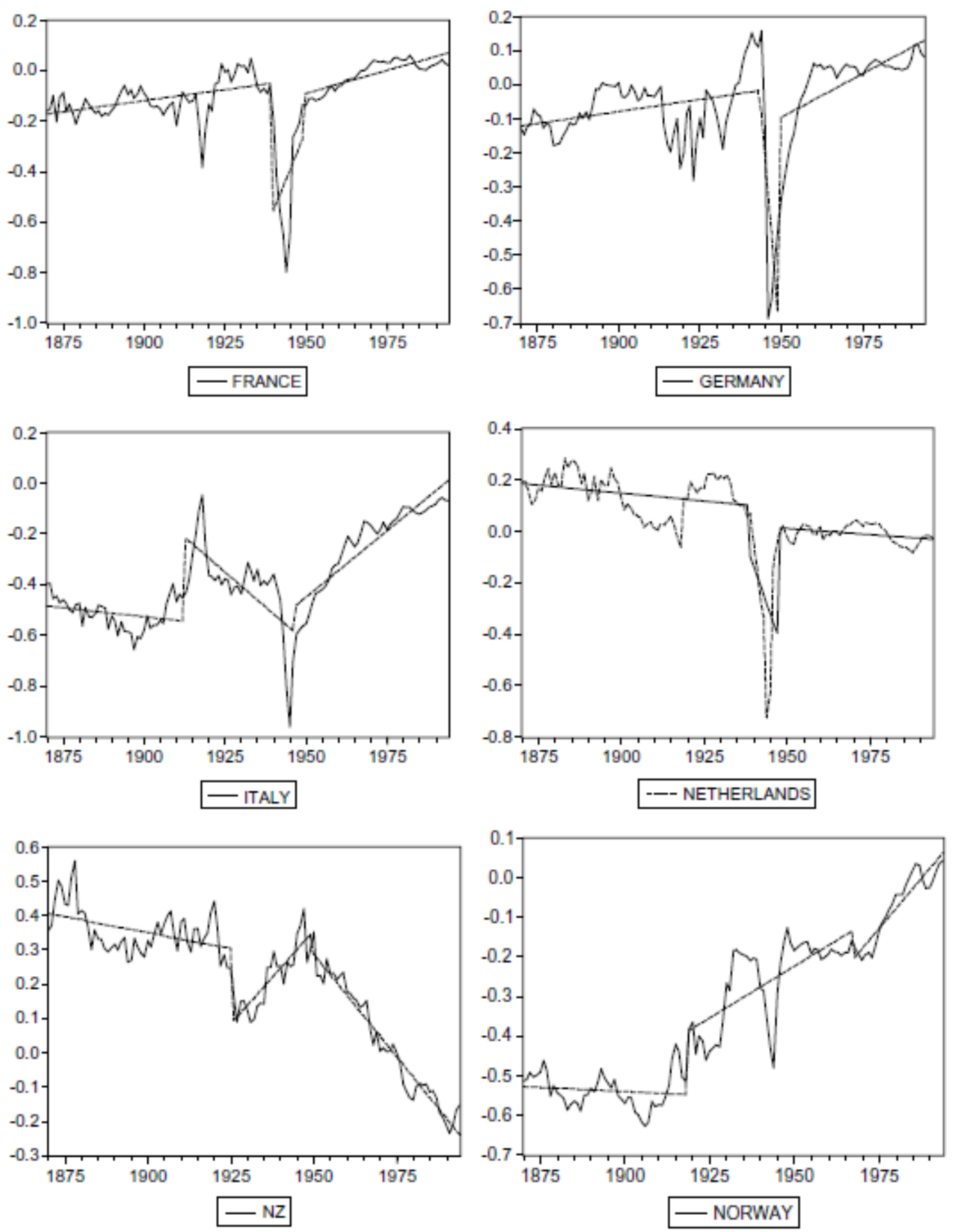

Fig. 1 (continued) 

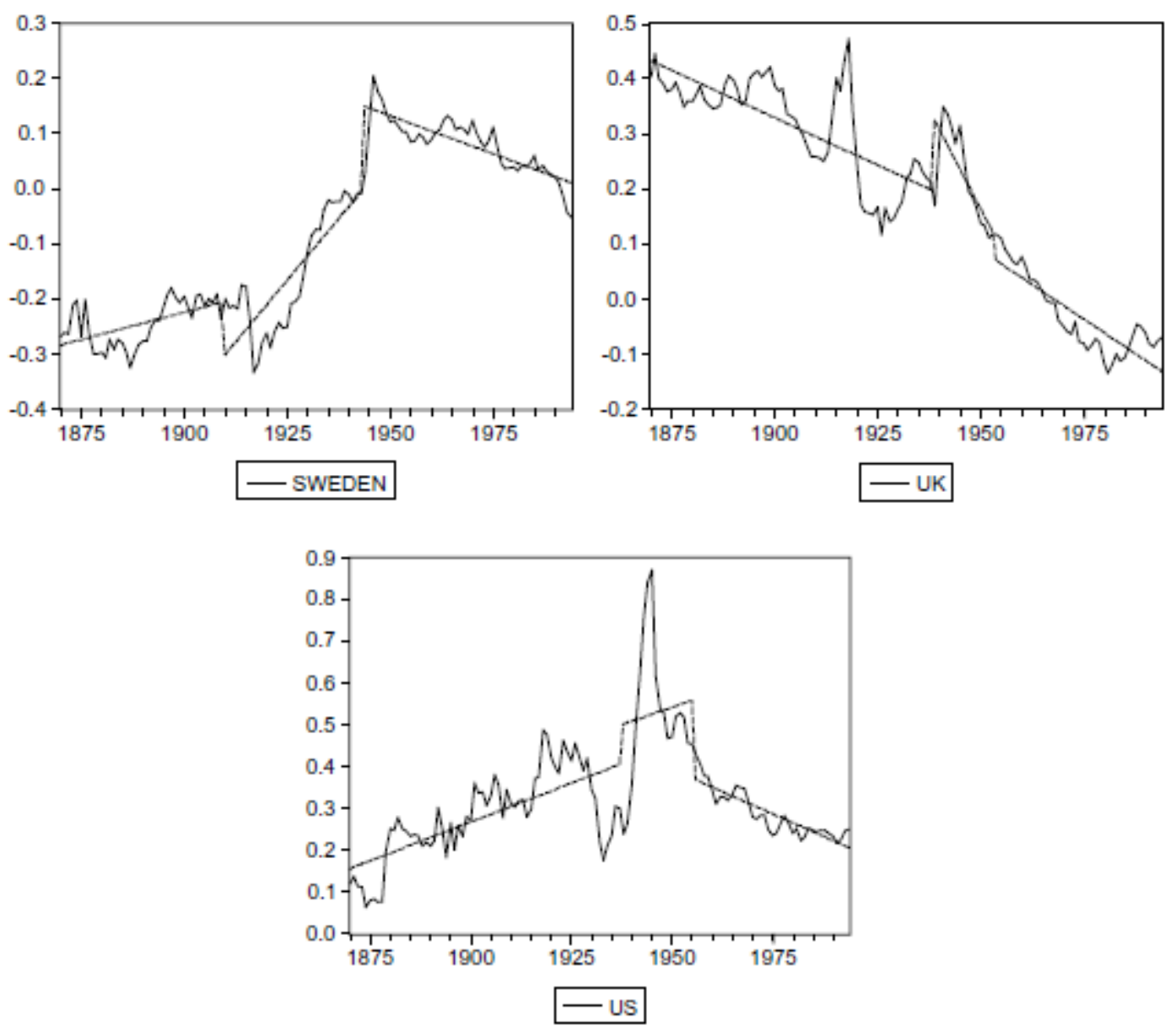

Fig. 1 (continued)

\section{STRUCTURAL BREAKS}

Examination of the break points in Table 1 and Table 2 reveals some interesting observations. ${ }^{12}$ In three countries (Canada, Norway, and New Zealand) the first structural break occurs around the World War I period of 1912-1927. In seven countries (Austria, Belgium, France, Germany, the Netherlands, the UK, and the US) the first structural break occurs around the World War II period of 1937-1949. In eight countries (Australia, Belgium, Canada, Denmark, France, the Netherlands, New Zealand, and Sweden) the second structural break occurs around the World War II period of 1938-1949. From the above, it is apparent that most structural breaks in relative incomes (67\%) occur around the two World Wars. The findings are similar for both preWWII originating sub-samples in Table 3 and Table 4.

What are the implications of structural breaks to our findings? Most important is the impact from increased ability to reject the unit root hypothesis. For example, whereas Bernard and Durlauf (1995) found little evidence of income convergence in long time series, after allowing for 
structural breaks we find significant support for convergence over a similar time period. This point is similarly noted by Fleissig and Strauss (2001) who suggest that structural breaks may be the reason why in spite of employing panel tests to increase power, they found little evidence of convergence in time series that begin prior to WWII. In context of the Solow growth model, the finding of significant structural breaks suggests that country-specific conditioning variables, such as the relative level of technology, can be permanently altered by major shocks. Following a major shock, the time path of relative income can be permanently altered.

\section{CONCLUSION}

Time series data from fifteen OECD countries are examined over the period 1870-1994 to test for evidence of stochastic convergence in per capita incomes. To perform our tests, we utilize a LM unit root test that endogenously determines two structural breaks in level and trend. Our empirical findings provide significant evidence that incomes are stochastically converging. These results contrast with other time series tests that did not allow for structural breaks. By allowing for two structural breaks in each country, our tests benefit from greater ability to reject a false unit root null. After controlling for breaks, we find that most shocks to relative incomes are temporary and incomes converge. One or two significant breaks are identified in each country and most often correspond to time periods around the two World Wars. The existence of breaks suggests that relative incomes are stochastically converging, but subject to a small number of significant shocks that permanently alter country-specific compensating differentials.

\section{NOTES}

2 . These cross-section studies test the notion of " $\beta$-convergence". Some recent papers note pitfalls of this test for convergence (see, e.g., Evans, 1996; Evans and Karras, 1996; Quah, 1996).

3. The two-break minimum LM unit root test for Model $\mathrm{C}$ remains free of size distortions and spurious rejections in the presence of a unit root with break(s). See Lee and Strazicich (2003) for a description of the asymptotic properties of this test.

4. See, e.g., Ng and Perron (1995). To perform our tests, we jointly determine both the location of breaks and the number of augmentation terms endogenously from the data prior to computing the LM unit root test statistic. Gauss codes for the two-break minimum LM test are available on the web site http://www.cba.ua.edu/ jlee/gauss.

5. While one might suggest allowing for more than two breaks in the unit root test we do not consider this possibility in this paper. In particular, the computational burden of identifying three or more break points, in conjunction with determining the optimal number of lagged augmented terms, would significantly increase. However, allowing for more than two breaks in the unit root test may not be a concern here since we find that, in general, two breaks is sufficient to reject the null. 
6. Eq. (4) implies that shocks of the same percentage common to all countries would leave relative incomes unchanged. Therefore, the structural breaks identified by our tests would be country-specific. In terms of convergence, any identified structural breaks would imply a permanent change in a country's compensating differential. Throughout, we require that each break be significant at the $10 \%$ level.

7. As previously noted, the LM unit root test allows for the possibility of structural breaks under the unit root null hypothesis. Therefore, in the testing regression $B_{j t}$ and $D_{j t}$ denote shifts in level and trend, respectively, under the alternative hypothesis and one period jumps in level and permanent shifts in level, respectively, under the null hypothesis. Note that the first break applies to $B_{1 t}$ and $D_{1 t}$ while the second break applies to $B_{2 t}$ and $D_{2 t}$, respectively.

8. To examine comparable results of not allowing for any breaks, we additionally applied the nobreak LM unit root test of Schmidt and Phillips (1992). The number of lagged augmented terms was again determined using the general to specific method. Not surprisingly, without allowing for breaks we could reject the null in only four of the fifteen countries: Denmark, France, Germany, and the Netherlands. This provides further evidence that failure to allow for structural breaks reduces the ability to reject a false unit root null. These results are available upon request.

9. We are grateful to an anonymous referee for this suggestion.

10.Theses results are available upon request.

11. Li and Papell (1999) utilize a Dickey-Fuller type endogenous one-break unit root test and find support for stochastic convergence of incomes for fourteen out of sixteen OECD countries. While they allow for one structural break in each time series, their tests are subject to the criticisms noted by Nunes et al. (1997) and Lee and Strazicich (2001). In particular, rejection of the null does not necessarily imply a stationary series with break, and, therefore convergence, but may imply a nonstationary series with break(s) and divergence. This outcome is due to the fact that their null hypothesis is a unit root without break.

12. This discussion refers to the two significant break points that were identified for twelve countries in Table 1 and one significant break point for the three remaining countries in Table 2.

\section{REFERENCES}

Barro, R.J., 1991. Economic growth in a cross section of countries. Quarterly Journal of Economics 106, 407-443.

Barro, R.J., Sala-i-Martin, X., 1991. Convergence across states and regions. Brookings Papers on Economic Activity (1), 107-182.

Barro, R.J., Sala-i-Martin, X., 1992. Convergence. Journal of Political Economy 100, 223-251. Baumol, W.J., 1986. Productivity growth, convergence and welfare: What the long-run data show. American Economic Review 76, 1075-1085. 
Bernard, A.B., Durlauf, S.N., 1995. Convergence in international output. Journal of Applied Econometrics 10, 97-108.

Carlino, G., Mills, L., 1993. Are US regional economies converging? A time series analysis. Journal of Monetary Economics 32, 335-346.

Evans, P., 1996. Using cross-country variances to evaluate growth theories. Journal of Economic Dynamics and Control 20, 1027-1049.

Evans, P., Karras, G., 1996. Convergence revisited. Journal of Monetary Economics 37, 249_ 265.

Fleissig, A., Strauss, J., 2001. Panel unit-root tests of OECD stochastic convergence. Review of International Economics 9, 153-162.

Lee, J., Strazicich, M.C., 1999. Minimum LM unit root test. Department of Economics, University of Central Florida Working Paper Series.

Lee, J., Strazicich, M.C., 2001. Break point estimation and spurious rejections with endogenous unit root tests. Oxford Bulletin of Economics and Statistics 63, 535-558.

Lee, J., Strazicich, M.C., 2003. Minimum LM unit root test with two structural breaks. The Review of Economics and Statistics 85, 1082-1089.

Li, Q., Papell, D., 1999. Convergence of international output: Time series evidence for 16 OECD countries. International Review of Economics and Finance 8, 267-280.

Loewy, M., Papell, D., 1996. Are US regional income converging? Some further evidence. Journal of Monetary Economics 38, 587-598.

Lumsdaine, R., Papell, D., 1997. Multiple trend breaks and the unit-root hypothesis. Review of Economics and Statistics 79, 212-218.

Maddison, A., 1995. Monitoring the World Economy 1820-1992. OECD Development Centre, Paris. Mankiw, N.G., Romer, D., Weil, D.N., 1992. A contribution to the empirics of economic growth. Quarterly Journal of Economics 107, 407-438.

$\mathrm{Ng}, \mathrm{S} .$, Perron, P., 1995. Unit root tests in ARMA models with data-dependent methods for the selection of the truncation lag. Journal of the American Statistical Association 90, 269-281.

Nunes, L., Newbold, P., Kuan, C.-M., 1997. Testing for unit roots with breaks: Evidence on the Great Crash and the unit root hypothesis reconsidered. Oxford Bulletin of Economics and Statistics 59, 435-448.

Perron, P., 1989. The Great Crash, the oil price shock, and the unit root hypothesis. Econometrica 57, 1361-1401.

Perron, P., 1997. Further evidence on breaking trend functions in macroeconomic variables. Journal of Econometrics 80, 355-385. 
Quah, D., 1990. International patterns of growth: Persistence in cross country disparities. Mimeo. Quah, D., 1996. Empirics for economic growth and convergence. European Economic Review 40, 1353-1375.

Schmidt, P., Phillips, P.C.B., 1992. LM tests for a unit root in the presence of deterministic trends. Oxford Bulletin of Economics and Statistics 54, 257-287.

Solow, R., 1956. A contribution to the theory of economic growth. Quarterly Journal of Economics 70, 65-94.

Zivot, E., Andrews, D.W.K., 1992. Further evidence on the great crash, the oil-price shock and the unit root hypothesis. Journal of Business and Economic Statistics 10, 251-270. 